\title{
ANALISIS PERKEMBANGAN TINGKAT KESEHATAN BPR XYZ TAHUN 2014 - 2016 DENGAN MENGGUNAKAN METODE CAMEL
}

\author{
Virnando Lie \\ Program Studi Magister Manajemen Universitas Tarumanagara \\ lievirnando@yahoo.com
}

\begin{abstract}
The rule of banking is very important in an economy because in its operational activities the bank has several functions, such as an intermediary functions that bridges the interests of the party who has excess fund (creditor funds) with the party in need of fund (borrower / debtor). Based on the provisions of Bank Indonesia that in order to maintain the security of cutomers, all Indonesian banking institution are obliged to report their performance to The Financial Service Authority (OJK) and always adhere to the provisions of the law prevailing in the region of Indonesia. Therefore all banking institution in Indonesia will be assessed its performance by using CAMEL Methods, with five aspects of banking assessment such as Capital, Assets, Managements, Earning and Liquidity. This assessment is quantitative descriptive research method. For the result, we used a primary data obtained through questionnaires and secondary data in the form of financial statements balance sheet and income statement of PT BPR XYZ between 2014 to 2016. According to health assessment Bank Perkreditan Rakyat (BPR), based on Decree of the Board of Directors of Bank Indonesia No.30/12/KEP/DIR/1997, The result of financial statement PT BPR XYZ of three years period (2014 - 2016) assessments and based on some benchmarks to determine the reliability of the bank after assessment of each variable, we found that the PT BPR XYZ has good banking performance (credit score more than 81 which is the minimum score of good banking performance).
\end{abstract}

Abstrak : Peranan perbankan sangat penting dalam suatu perekonomian karena dalam kegiatan operasionalnya bank mempunyai beberapa fungsi antara lain sebagai fungsi intermediasi yang menjembatani kepentingan pihak yang memiliki kelebihan dana (penyimpan dana/kreditur) dengan pihak yang membutuhkan dana (peminjam/debitur). Sesuai dengan ketetapan Bank Indonesia bahwa demi menjaga keamanan para nasabahnya,perbankan di Indonesia wajib selalu melaporkan kinerjanya kepada Otoritas Jasa Keuangan (OJK)dan selalu mematuhi ketentuan perundangan yang berlaku di wilayah hukum di Indonesia. Sehingga semua lembaga perbankan yang telah terdaftar di OJK akan dinilai kinerjanya dengan menggunakan metode CAMEL, dengan lima aspek pernilaian perbankan antara lain mengenai aspek capital (permodalan), aspek asset (kualitas aktiva), aspek manajemen, aspek earning (rentabilitas) dan aspek liquidity (likuiditas).

Penelitian ini bersifat kuantitatif deskriptif, untuk penelitian ini, jenis data yang digunakan adalah data primer yang diperoleh dari pertanyaan dan data sekunder yaitu laporan keuangan berupa neraca dan laba rugi PT BPR XYZ antara tahun 2014 sampai 2016. Mengacu pada penilaian tingkat kesehatan BPR berdasarkan keputusan Dewan Direktur Bank Indonesia No. 30/12/KEP/DIR/1997, penelitian atas laporan keuangan yang telah dilakukan terhadap PT BPR XYZ untuk periode 3 tahun (2014 - 2016) diperoleh bahwa beberapa tolak ukur untuk menentukan tingkat kesehatan suatu bank setelah dilakukan penilaian terhadap masingmasing variabel, dapat disimpulkan bahwa tingkat kesehatan PT BPR XYZ mendapat predikat SEHAT( karena nilai kredit CAMEL yang diperoleh lebih dari 81, yang merupakan batas nilai minimum untuk kategori sehat).

Keywords : Health Assessment BPR, Capital, Assets, Management, Earning, Liquidity factors. 


\section{PENDAHULUAN}

Peranan perbankan sangat penting dalam suatu perekonomian. Bank yang sehat adalah bank yang dapat menjaga dan memelihara kepercayaan masyarakat, dapat menjalankan fungsi intermediasi, dapat membantu kelancaran lalu lintas pembayaran serta dapat dipergunakan pemerintah dalam melaksankan berbagai kebijakan, terutama kebijakan moneter. Berdasarkan UU No.10 Tahun 1998 tentang perbankan, bank wajib memelihara tingkat kesehatan sesuai dengan ketentuan kecukupan modal, kualitas asset, kualitas manajemen, likuiditas, rentabilitas dan solvabilitas serta aspek lain yang berkaitan dengan usaha bank dan wajib melakukan kegiatan usaha sesuai dengan prinsip kehati-hatian.

Penilaian tingkat kesehatan bank di Indonesia secara garis besar didasarkan pada faktor CAMEL yaitu sehimpun indikator yang berunsurkan variable Capital, Assets, Management, Earnings dan Liquidity. Tujuan dilakukan penilaian tingkat kesehatan bank yaitu untuk mengetahui kondisi suatu bank pada saat ini dan yang akan datang. Bagi perbankan hasil akhir penilaian digunakan sebagai sarana menetapkan strategi usaha di waktu yang akan datang, sedangkan bagi Bank Indonesia digunakan sebagai sarana penetapan dan implementasi pengawasan bank.

\section{TUJUAN PENELITIAN}

Tujuan dari penelitian ini adalah : menganalisis dan melakukan perhitungan tingkat kesehatan BPR XYZ dengan menggunakan metode CAMEL (Capital, Assets, Management, Earnings dan Liquiduity) untuk periode tahun 2014 - 2016, serta untuk mengetahui kinerja dan kondisi BPR XYZ dilihat dari tingkat kesehatannya apakah termasuk kategori bank yang sehat atau tidak.

\section{TINJAUAN PUSTAKA}

Beberapa penelitian sejenis yang pernah dilakukan yaitu penelitian yang dilakukan oleh Sri Pujiyanti (2010), Analisis Kinerja Keuangan Mengenai Tingkat Kesehatan Bank Dengan Menggunakan Metode CAMEL (Studi kasus pada PT Bank Negara Indonesia Tbk dan PT Bank Bukopin Tbk periode 2006 -2008 ), kedua bank tersebut dapat dikatakan sehat, tetapi jika dibandingkan dengan tingkat kesehatan kedua bank tersebut maka PT Bank Bukopin Tbk lebih sehat dibandingkan dengan PT Bank Negara Indonesia Tbk. Hal ini dapat dilihat dari aspek Asset, Management, Earnings dan Liquidity yang dimiliki Bank Bukopin Tbk lebih baik dari pada PT Bank Negara Indonesia Tbk.

\section{Pengertian Bank}

Pengertian bank menurut UU No 10 Tahun 1998 Tanggal 10 November 1998 tentang perbankan adalah badan usaha yang menghimpun dana dari masyarakat dalam bentuk simpanan dan menyalurkannya kepada masyarakat dalam bentuk kredit dan atau bentukbentuk lainnya dalam rangka meningkatkan taraf hidup rakyat.

Adapun jenis-jenis perbankan yang telah diatur dalam UU Perbankan No.7 Tahun 1992 dan ditegaskan kembali dengan dikeluarkannya UU No.10 Tahun 1998, terdiri dari 2 jenis yaitu : Bank Umum, yaitu bank yang melaksanakan kegiatan usaha secara konvensional dan atau berdasarkan syariah yang dalam kegiatannya memberikan jasa dalam lalu lintas pembayaran dan Bank Perkeditan Rakyat (BPR), yaitu bank yang melaksanakan kegiatan usaha secara konvesional atau berdasarkan prinsip syariah yang dalam kegiatannya tidak memberikan jasa dalam lalu lintas pembayaran.

\section{Laporan Keuangan}


Menurut Anderson (1988), Laporan Keuangan pada dasarnya adalah hasil dari proses akuntansi yang dapat digunakan sebagai alat untuk berkomunikasi antara data keuangan atau aktifitas suatu perusahaan dengan pihak-pihak yang berkepentingan dengan atau aktivitas perusahaan. Jadi dapat disimpulkan bahwa laporan keuangan merupakan informasi historis dimana informasi yang disajikan terbatas dan dalam penggunaannya diperlukan penafsiranpenafsiran yang memerlukan analisa terlebih dahulu sehingga dapat memberikan informasi yang lebih mendalam bagi para pemakai dalam mengambil keputusan.

\section{Penilaian Tingkat Kesehatan Dengan Metode CAMEL}

Menurut Riyaldi (2009), Tingkat kesehatan bank adalah penilaian atas suatu kondisi laporan keuangan bank pada periode dan saat tertentu sesuai dengan standard Bank Indonesia. Metode atau atau cara penilaian tersebut dikenal dengan metode CAMEL.

Tata cara penilaian tingkat kesehatan yang digunakan adalah Surat Keputusan Direksi Bank Indonesia No.30/12/KEP/DIR/1997 Tanggal 30 April 1997 Tentang Tata Cara Penilaian Tingkat Kesehatan Bank Perkreditan Rakyat. Faktor-faktor yang mencakup penilaian yaitu: Faktor Permodalan (Capital), Faktor Kualitas Aktiva Produktif (Assets), Faktor Manajemen (Management), Faktor Rentabilitas (Earnings) dan Faktor Likuiditas (Liquidity)

\section{METODE PENELITIAN}

Dengan menggunakan pendekatan kuantitatif deskriptif, penulis melakukan analisis kinerja keuangan PT BPR XYZ dengan meneliti laporan keuangannya dari tahun 2014 2016 dengan metode CAMEL. Adapun faktor-faktor yang dianalisis meliputi faktor : C (Capital), A (Asset), M (Management), E (Earning) dan L (Liquidity), sesusi dengan Surat Keputusan Direksi Bank Indonesia No.30/12/KEP/DIR/1997 tanggal 30 April 1997 Tentang Tata cara Penilaian Tingkat Kesehatan Bank Perkreditan Rakyat, yaitu :

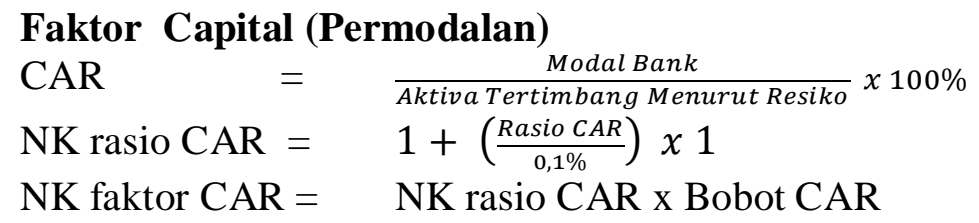

Tabel

Kriteria Penilaian Rasio Capital Adequacy Ratio (CAR)

\begin{tabular}{|cc|}
\hline Nilai Kredit & Predikat \\
\hline$>8 \%$ & Sehat \\
\hline $7,9 \%-8 \%$ & Cukup Sehat \\
\hline $6,5 \%<7,9 \%$ & Kurang Sehat \\
\hline$<6,5 \%$ & Tidak Sehat \\
\hline
\end{tabular}

\section{Faktor Assets ( Kualitas Aktiva Produktif )}

Faktor Asset diperhitungkan dengan 2 rasio yaitu rasio KAP dan rasio PPAP, yaitu Rasio aktiva produktif yang diklasifikasikan terhadap jumlah aktiva produktif.

$\begin{array}{ll}\text { Rasio KAP }= & \frac{\text { Aktiva Produktif yang diklasifikasikan }}{\text { Total Aktiva Produktif }} \times 100 \% \\ \text { NK rasio KAP }= & \frac{22,5 \%-\text { Rasio KAP }}{0,15 \%} \\ \text { NK faktor KAP }= & \text { NK rasio KAP x Bobot KAP }\end{array}$

Tabel 
Kriteria Penilaian Rasio Kualitas Aktiva Produktif (KAP)

\begin{tabular}{|cc|}
\hline Nilai Kredit & Predikat \\
\hline $0,0 \%<10,35 \%$ & Sehat \\
\hline $10,35 \%-12,6 \%$ & Cukup Sehat \\
\hline $12,61 \%-14,85 \%$ & Kurang Sehat \\
\hline$>14,86 \%$ & Tidak Sehat \\
\hline
\end{tabular}

Rasio penyisihan penghapusan aktiva produktif (PPAP) terhadap penyisihan penghapusan aktiva produktif yang wajib dibentuk (PPAPWD)

Rasio PPAP $=\frac{P P A P}{P P A P W D} \times 100 \%$

$\mathrm{NK}$ rasio PPAP $=\frac{\text { Rasio } P \text { PAP }}{1 \%} \times 1$

NK faktor PPAP $=\quad$ NK rasio PPAP $x$ Bobot PPAP

Tabel

Kriteria Penilaian Rasio Penyisihan Penghapusan Aktiva Produktif (PPAP)

\begin{tabular}{|cc|}
\hline Nilai Kredit & Predikat \\
\hline$>81,0 \%$ & Sehat \\
\hline $66,0 \%-81,0 \%$ & Cukup Sehat \\
\hline $51,0 \%-65,9 \%$ & Kurang Sehat \\
\hline$<51 \%$ & Tidak Sehat \\
\hline
\end{tabular}

\section{Faktor Manajemen}

Kuantifikasi penilaian kesehatan terhadap faktor manajemen memakai system kredit.Perhitungan nilai kredit di dasarkan pada hasil penilaian jawaban pertanyaanpertanyaan dari komponen manajemen yang secara keseluruhan terdiri dari 25 pertanyaan. Penilaian didasarkan pada 2 aspek, yaitu :

1. Manajemen Umum, meliputi penilaian terhadap Manajemen strategi, struktur, system dan manajemen kepemimpinan dengan jumlah keseluruhan 10 pertanyaan.

2.Manajemen Resiko, meliputi penilaian terhadap 5 resiko yaitu resiko likuiditas, resiko kredit, resiko operasional, resiko hukum serta resiko pemilik dan Pengurus. dengan jumlah seluruh 15 pertanyaan .

Perhitungan nilai kredit $(\mathrm{NK})$ untuk setiap pertanyaan manajemen diberi nilai 0 sampai dengan 4 dengan kreteria sebagai berikut :

Nilai $0=$ Kondisi Lemah Nilai 1-3= Kondisi antara Nilai 4= Kondisi Baik

NK faktor manajemen $=$ NK manajemen $\mathrm{x}$ Bobot rasio manajemen .

Tabel

Kriteria Penilaian Manajemen

\begin{tabular}{|cc|}
\hline Nilai Kredit & Predikat \\
\hline$>81$ & Sehat \\
\hline$\geq 66-<81$ & Cukup Sehat \\
\hline$\geq 51-<66$ & Kurang Sehat \\
\hline$<51$ & Tidak Sehat \\
\hline
\end{tabular}

Faktor Earning (Rentabilitas) 
Dalam melakukan penilaian terhadap komponen faktor rentabilitas peneliti menggunakan 2 rasio yaitu :

Rasio Return on Asset (ROA), rasio laba kotor terhadap total aktiva :

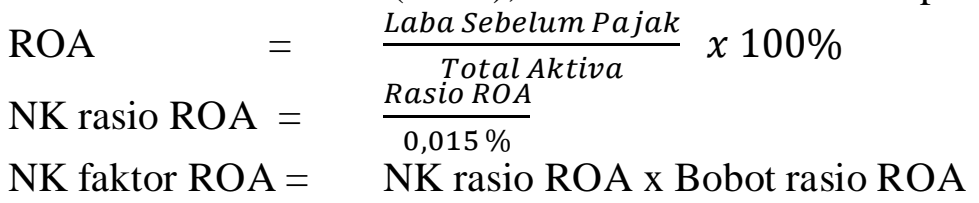

Tabel

Kriteria Penilaian Rasio Return on Asset (ROA)

\begin{tabular}{|cc|}
\hline Nilai Kredit & Predikat \\
\hline$>1,22 \%$ & Sehat \\
\hline $0,99 \%-1,21 \%$ & Cukup Sehat \\
\hline $0,77 \%-0,98 \%$ & Kurang Sehat \\
\hline$<0,76 \%$ & Tidak Sehat \\
\hline
\end{tabular}

Rasio BOPO, rasio biaya operasional terhadap Pendapat Operasional (BOPO),

BOPO $=\frac{\text { Biaya Operasional }}{\text { Pendapatana Operasional }} \times 100 \%$

$\mathrm{NK}$ rasio $\mathrm{BOPO}=\frac{100 \%-\text { Rasio } B O P O}{0,08 \%} \times 1$

$\mathrm{NK}$ faktor $\mathrm{BOPO}=\mathrm{NK}$ rasio $\mathrm{BOPO} \times$ Bobot rasio $\mathrm{BOPO}$

Tabel

Kriteria Penilaian Rasio BOPO

\begin{tabular}{|cc|}
\hline Nilai Kredit & Predikat \\
\hline$<93,52 \%$ & Sehat \\
\hline $93,52 \%-94,73 \%$ & Cukup Sehat \\
\hline $94,73 \%-95,92 \%$ & Kurang Sehat \\
\hline$>95,92 \%$ & Tidak Sehat \\
\hline
\end{tabular}

\section{Faktor Likuiditas}

Faktor likuiditas diperhitungan dengan 2 rasio yaitu :

Rasio cash ratio (CR), rasio alat likuiditas terhadap hutang.

$\begin{array}{lll}\text { Cash Ratio } & \frac{\text { Alat Likuid }}{\text { Hutang Lancar }} \times 100 \% \\ \text { NK kredit Cash Ratio } & \quad & \text { Rasio CR : 0,05\% } \\ \text { NK faktor BOPO } & \quad & \text { NK Cash Ratio x Bobot rasio CR }\end{array}$

Tabel

Kriteria Penilaian Cash Ratio (CR)

\begin{tabular}{|cc|}
\hline Nilai Kredit & Predikat \\
\hline$\geq 4,05 \%$ & Sehat \\
\hline$\geq 3,33 \%-<4,05 \%$ & Cukup Sehat \\
\hline$\geq 2,55 \%-<3,30 \%$ & Kurang Sehat \\
\hline$<2,55 \%$ & Tidak Sehat \\
\hline
\end{tabular}


Loan to Deposit Ratio, rasio kredit yang diberikan terhadap dana yang diterima.

$$
\begin{aligned}
\text { LDR } & =\frac{\text { Kredit yang diberikan }}{\text { Dana yang diterima }} \times 100 \% \\
\mathrm{NK} \text { rasio LDR } & =\frac{115 \%-\text { Rasio LDR }}{0,25 \%} \\
\mathrm{NK} \text { faktor LDR } & =\mathrm{NK} \text { rasio LDR } \times \text { Bobot rasio LDR }
\end{aligned}
$$

Tabel

Kriteria Penilaian Loan to Deposit Ratio ( LDR )

\begin{tabular}{|cc|}
\hline Nilai Kredit & Predikat \\
\hline$\leq 94,75 \%$ & Sehat \\
\hline$>94.75 \%-98,50 \%$ & Cukup Sehat \\
\hline$>98,50 \%-102,25 \%$ & Kurang Sehat \\
\hline$>102,25 \%$ & Tidak Sehat \\
\hline
\end{tabular}

Tabel

Predikat Tingkat Kesehatan BPR

\begin{tabular}{|cc|}
\hline Total Nilai (Bobot Faktor) & Predikat \\
\hline $81-100$ & Sehat \\
\hline $66-<81$ & Cukup Sehat \\
\hline $51-<66$ & Kurang Sehat \\
\hline $0-<51$ & Tidak Sehat \\
\hline
\end{tabular}

\section{ANALISIS DAN PEMBAHASAN}

Penelitian tingkat kesehatan BPR XYZ secara keseluruhan dilakukan dengan analisis kuantitatif, yaitu analisis yang dilakukan dengan cara mengkuantitatifkan aspek-aspek yang termasuk dalam CAMEL, sehingga diperoleh suatu nilai tertentu. Adapun hasil rekapitulasi penilaian tingkat kesehatan BPR XYZ untuk periode 2014 - 2016 :

\begin{tabular}{|c|c|c|c|c|c|}
\hline No & $\begin{array}{l}\text { Faktor yang } \\
\text { dinilai }\end{array}$ & Komponen & $\begin{array}{l}\text { Tahun } \\
2014 \\
(1)\end{array}$ & $\begin{array}{l}\text { Tahun } \\
2015\end{array}$ & $\begin{array}{l}\text { Tahun } \\
2016\end{array}$ \\
\hline 1. & $\begin{array}{l}\text { Capital } \\
\text { (Permodalan) }\end{array}$ & CAR & $17,8 \%$ & $13,68 \%$ & $13,28 \%$ \\
\hline 2. & Assets & $\begin{array}{l}\text { 1. KAP } \\
\text { 2. PPAP }\end{array}$ & $\begin{array}{l}3,49 \% \\
100 \%\end{array}$ & $\begin{array}{l}2,82 \% \\
100 \%\end{array}$ & $4,09 \%$ \\
\hline 3. & Manajemen & $\begin{array}{lcl}\text { Total nilai } & \text { Manajemen } \\
\text { Umum } & \& & \text { Manajemen } \\
\text { Resiko } & & \\
\end{array}$ & 67 point & 74 point & 69 point \\
\hline 4. & Earning & $\begin{array}{l}\text { 1. } \mathrm{ROA} \\
\text { 2. BOPO }\end{array}$ & $\begin{array}{r}2,42 \% \\
89,67 \% \\
\end{array}$ & $\begin{array}{l}3,1 \% \\
86,37 \%\end{array}$ & $\begin{array}{l}2,85 \% \\
85,13 \%\end{array}$ \\
\hline 5. & Liquidity & $\begin{array}{l}\text { 1. Cash Rasio } \\
\text { 2. LDR }\end{array}$ & $\begin{array}{l}21,16 \% \\
79,57 \%\end{array}$ & $\begin{array}{l}17,26 \% \\
81,02 \%\end{array}$ & $\begin{array}{l}42,72 \% \\
67,02 \%\end{array}$ \\
\hline & Total Nilai & Faktor CAMEL & 93,4 & 94,8 & 93,8 \\
\hline & $\begin{array}{l}\text { Predikat } \\
\text { Tingkat }\end{array}$ & Kesehatan & Sehat & Sehat & Sehat \\
\hline
\end{tabular}

Tabel

Rekapitulasi Penilaian Tingkat Kesehatan PT BPR XYZ Tahun 2014 -2016

Dari hasil perhitungan pada tabel 10 dapat dilihat perkembangan penilaian tingkat kesehatan bank PT BPR XYZ antara lain : Faktor permodalan untuk periode tahun 2014 - 2016 masing- 
masing sebesar 17,8 \%, 13,68 \% dan 13,28\%. Hasil rasio ini termasuk dalam kategori sehat, yakni diatas ketentuan yang berlaku sebesar $>8 \%$. Faktor Kualitas Asset Produktif (Assets) menggunakan 2 rasio yakni rasio KAP dengan nilai masing-masing 3,49 \%, 2,82\% dan 4,09 $\%$ yang masuk dalam kategori sehat, dan rasio PPAP yang rasionya semuanya $100 \%$ juga masuk dalam kategori Sehat. Sehingga untuk faktor penilaian atas kualitas asset produktif (KAP) masuk dalam kategori sehat, hal ini mencerminkan bahwa kredit-kredit yang diberikan masih tergolong cukup baik dan lancar. Untuk faktor manajemen masuk dalam kategori cukup sehat, yakni manajemen memiliki track record yang cukup baik serta mampu mengatasi masalah yang dihadapi baik saat ini maupun saat yang akan datang dan memiliki sistem pengendalian resiko yang cukup baik. Untuk faktor rentabilitas menggunakan 2 rasio yaitu rasio ROA dengan nilai masing-masing sebesar 2,42 \%, 3,1\% dan 2,85\% yang kesemuanya ini masuk dalam kategori sehat. Dan rasio BOPO dengan nilai masing-masing $89,67 \%, 86,37 \%$ dan $85,13 \%$ juga masuk dalam kategori sehat. Faktor rentabilitas ini menunjukkan bahwa PT BPR XYZ dalam mengelolah seluruh aktivanya cukup baik tercermin dari kemampuan dalam menciptakan laba serta efisiensi dalam pengeluaran biaya operasional. Terakhir Faktor likuiditas juga terdiri atas 2 rasio yaitu cash rasio (CR) yakni masing-masing sebesar $21,16 \%, 17,26 \%$ dan $42,72 \%$ yang kesemuanya masuk dalam kategori sehat, dan rasio LDR masing-masing sebesar 79,57 \%, 81,02\% dan 67,02\% masuk dalam kategori sehat. Hal ini menunjukkan bahwa PT BPR XYZ memiliki kinerja likuiditas yang baik serta kemampuan likuiditas yang baik guna mengantisipasi kebutuhan likuiditas.

\section{KESIMPULAN DAN SARAN}

\section{Kesimpulan}

Dari analisa diatas dapat dapat disimpulkan bahwa Perkembangan tingkat kesehatan bank PT BPR XYZ untuk periode 2014 - 2016 berdasarkan komponen Capital, Assets, Management, Earning dan Liquidity (CAMEL) hasil nilai yang diperoleh yaitu masingmasing sebesar 93,4,94,8, dan 93,8, yang mana dari semua periode ini tingkat kesehatan (TKS) yang diperoleh masuk dalam kategori sehat yakni melebihi dari nilai 81.

\section{Saran}

- $\quad$ PT BPR XYZ sebaiknya memiliki jajaran manajemen dengan kemampuan merancang strategi usaha dalam hal pengelolaan operasional maupun BPR yang semakin ketat.

- Kualitas aktiva produktif sebaiknya cepat diperbaiki melalui penyelesaian terhadap kredit-kredit bermasalah, melakukan penagihan secara intensif, meningkatkan pembinaan serta pemantauan terhadap usaha debitur.

- Pengelolaan - pengelolaan terhadap kecukupan modal, kualitas asset, manajemen pencapaian rentabilitas, kestabilan likuiditas dengan baik dan konsisten terhadap apa yang telah dibuat dalam rencana kerja tahunan.

- Jajaran pemegang saham diharapkan agar dapat melakukan penambahan modal ke dalam perusaahan agar rasio kecukupan modal lebih kuat dan untuk mengantinsipasi apabila ada peningkatan pada kualitas aktiva produktif yang digolongkan bermasalah.

- Pemberian kredit harus lebih ditingkatkan mengingat hampir sebagian besar laba bank diperoleh dari sisi pemberian kredit.

- Meningkatkan prinsip kehati-hatian dalam pemberian kredit yang baru dengan menganalisa faktor $5 \mathrm{C}$ secara baik dan benar serta melakukan monitoring usaha secara rutin supaya dapat mengurangi atau menekan resiko kredit bermasalah (NPL) yang akan timbul dikemudian hari.

- Peningkatan kualitas SDM melalui program-program yang terarah, baik menyangkut sistem rekrutmen, pelatihan-pelatihan, kompetensi untuk tingkat jabatan tertentu dan 
program-program lain yang dapat meningkatkan wawasan dan motivasi para karyawan.

- Mengembangkan teknologi information sistem (IT) sesuai dengan perkembangan saat ini baik dalam sistem operasional maupun dalam sistem pemasaran guna menghadapi era digitalisasi saat ini.

\section{DAFTAR PUSTAKA}

Bank Indonesia. (1998). UU No.10 Tahun 1998, tentang perubahan terhadap UU No. 7 tahun 1992, Jakarta

Bank Indonesia. (1997). Keputusan Direksi BI No.30/12/KEP/DIR tanggal 30 April 1997 tentang Tata Cara Penilaian Tingkat Kesehatan Bank Perkreditan Rakyat, Jakarta.

Ikatan Akuntansi Indonesia. (2006). Pernyataan Standar Akuntansi Keuangan. Jakarta : Penerbit Salemba Empat Patria

Kasmir (2002). Manajemen Perrbankan. Jakarta : Penerbit PT Raja Frafindo Persada.

Needles Belverd E., Anderson, Hendry R., Cadwell, James C. (1988). Financial \& Managerial Accounting. Houghton Miffin Co. Boston Princetown, New Jersey.

Otoritas Jasa Keuangan. (2014). Peraturan Otorotas Jasa Keuangan No.20/POJK/03/2014, tentang Bank Perkreditan Rakyat, Jakarta.

PT BPR XYZ. (2014-2016). Laporan Keuangan December 2014 -2016.

Pujiyanti, Sri dkk. (2010). Analisis Kinerja Keuangan Mengenai Tingkat Kesehatan Bank Dengan Menggunakan Metode CAMEL (Studi Kasus PT Bank Negara Indonesia Tbk dan PT Bank Bukopin Tbk Periode 2006-2008) Jurnal Ilmiah Universitas Gunadarma

Riyaldi. (2009). Membaca Neraca Bank .Edisi ke 2. Jakarta : Penerbit CV Karya Gemilang. Siamat, Dahlan (1993). Manajemen Bank Umum. Jakarta : Penerbit Salemba Empat.

Sugiyono.(2005). Metode Penelitian. Jakarta : Penerbit : Alfabeta

Susilo,Sri,dkk. (2000). Bank dan Lembaga Keuangan Lain.Jakarta : Penerbit Salemba Empat. Suyatno, Thomas, dkk. (1991). Kelembagaan Perbankan.Jakarta : Penerbit Gramedia.

Weston J. Fred \& Copeland, Thomas E. (1995). Manajemen Keuangan Jilid 1, Edisi ke 9. Penerbit : Bina Rupa Aksara. 
